American Journal of Applied Sciences 7 (11): 1449-1457, 2010

ISSN 1546-9239

(C) 2010 Science Publications

\title{
Renal Actions of Neutral Endopeptidase Inhibition in Rats with Chronic Heart Failure
}

\author{
${ }^{1}$ Amr M. Abbas, ${ }^{2}$ Ayman Z. Elsamanoudy and ${ }^{2}$ Adel Zalata \\ ${ }^{1}$ Department of Medical Physiology, \\ ${ }^{2}$ Department of Medical Biochemistry, \\ Faculty of Medicine, Mansoura University, Egypt
}

\begin{abstract}
Problem statement: We aim to evaluate the effects of acute and chronic inhibition of Neutral EndoPeptidase (NEP), by ONO-9902, on plasma and renal NEP gene expression, hemodynamic and renal parameters in rats with Chronic Heart Failure (CHF) following left Coronary Artery Ligation (CAL). Approach: Forty eight male Sprague-Dawley rats (220-240 g) were divided into sham and CAL groups. Myocardial infarction was induced by left CAL. All rats were further subdivided into untreated and orally treated with ONO-9902 (300 mg kg$\left.{ }^{-1} \mathrm{day}^{-1}\right)$ from the 1st to 6th weeks after the operation. At the 1st and 6th weeks after the operation, gene expression of plasma and renal NEP, plasma ANP, cGMP and aldosterone concentrations, urine volume, Na and ANP excretion, creatinine clearance and renal cGMP generation were measured. Results: CAL leads to sodium and water retention, increased renal NEP gene expression, plasma ANP and aldosterone and decreased renal cGMP generation and plasma NEP gene expression. Acute treatment of CAL rats by ONO-9902, at the 1st week after the operation, inhibited plasma and renal NEP gene expression with increased plasma ANP, which caused diuresis, natriuresis and increased renal cGMP generation. Moreover, chronic treatment of those rats by ONO-9902 decreased plasma and renal NEP gene expression, plasma aldosterone, increased plasma ANP but non significantly, and caused diuresis, natriuresis with increased renal cGMP generation. GFR was not significantly changed before or after treatment. Conclusion: Chronic treatment with NEP inhibitor decreases Na and water retention in rats with CHF by enhancing ANP action and suppressing aldosterone secretion. So, ONO-9902 may offer a new therapeutic approach in patients with CHF.
\end{abstract}

Key words: Chronic Heart Failure (CHF), atrial natriuretic peptide, neutral endopeptidase (NEP), Renin-Angiotensin-Aldosterone System (RAAS), Coronary Artery Ligation (CAL), Glomerular Filtration Rate (GFR), Atrial Natriuretic Peptide (ANP), Brain Natriuretic Peptide (BNP), Mean Arterial Pressure (MAP)

\section{INTRODUCTION}

Chronic Heart Failure (CHF) is a pathophysiological condition characterized by avid sodium retention with increased cardiac volume and pressure overload, peripheral edema, activation of the Renin-Angiotensin-Aldosterone System (RAAS), adrenergic system and reduced renal function despite elevation of endogenous natriuretic peptides (atrial and brain natriuretic peptides: ANP and BNP) (Palazzuoli and Nuti, 2010). Indeed, increased sodium retention with edema formation is a hallmark of CHF underscoring a key role of the kidney in this disorder (Sica, 2006).

The natriuretic peptides are a family of three peptide hormones; Atrial Natriuretic Peptide (ANP),
Brain Natriuretic Peptide (BNP) and C-type Natriuretic Peptide (CNP) (Lainscak et al., 2009). Under physiological conditions, ANP is synthesized in the atria, whereas BNP is produced by atrial and ventricular cardiomyocytes (Kilic et al., 2007; Al-Attar, 2010). The main actions of ANP and BNP include natriuresis, diuresis and inhibition of the renin-angiotensinaldosterone system (Clerico and Emdin, 2004). In heart failure, plasma concentration of ANP and BNP is elevated (Wei et al., 1993). Moreover, previous studies demonstrated that cardiac ANP and BNP mRNA was induced in heart failure. Both peptides become important to counteract the water and sodium retention and to decrease the peripheral vasoconstriction, which are induced in heart failure by an activated reninangiotensin-aldosterone system and by vasopressin (Arnolda et al., 1991).

Corresponding Author: Amr M. Abbas, Department of Medical Physiology, Faculty of Medicine, Mansoura University, Egypt Tel: 0020101545048 
It has been reported that infusion of ANP or BNP decreased both preload and afterload and increased cardiac output in patients with congestive heart failure whose plasma concentrations of ANP and BNP had already been high as compared with those of normal subjects (Colucci et al., 2000). These findings imply that only a high level of endogenous ANP and BNP would not improve the pathophysiology of heart failure and that an additional increase in these peptides may be necessary to elicit the improvement. However, the therapeutic potential of ANP and BNP themselves is limited because these peptides are inactive in an oral administration and are short-acting after intravenous administration. Thus, an orally active analogue of drugs that can inhibit ANP degradation would be expected to be useful for the therapy of CHF (Maki et al., 2001).

ANP is inactivated rapidly in vivo. One important metabolic pathway of its inactivation involves enzymatic degradation by neutral endopeptidase (NEP); also called enkephalinase, (EC3.4.24.11) (Maki et al., 2000). NEP is a zinc-containing membrane-bound enzyme that is widely distributed in organs, particularly in the kidney and lungs (Sansoe et al., 2006) Since NEP plays a major role in the clearance of ANP under pathological conditions where there is a higher plasma concentration as in CHF (Hashimoto et al., 1994), NEP inhibition is regarded as a process of maintaining the biological activity of endogenous ANP by preventing its degradation. Therefore, inhibition of the ANP degradation by treatment with NEP inhibitor would be expected to exert beneficial effects on $\mathrm{CHF}$ because of amplification of the ANP action.

The aim of the current work was to investigate the effect of acute and long term (chronic) inhibition of NEP with the orally administered ONO-9902, enkephalinase inhibitor anti-nociceptive agent (Yamamori et al., 1996), on plasma and renal NEP gene expression, haemodynamic and renal parameters in rats with CHF following left CAL.

\section{MATERIALS AND METHODS}

Substances: ONO-9902, $(4 S)-4-[(2 S)$-benzyl-3-[(1RS)1,3-dihydro-3-isobenzofuranyl -1-thio] propionylamino]-4-( $N$-phenylcarbamoyl)-butyric acid (Sigma, St. Louis, MO, USA).

Animals: Sixty male Sprague dawley rats weighing 220-240 g were purchased from Vaccine and Immunization Authority (Helwan, Cairo, Egypt) and housed (Animal House, Medical Physiology department, Faculty of Medicine, Mansoura University, Egypt) under controlled conditions (temperature $23 \pm 1^{\circ} \mathrm{C}$ and a $12: 12$ light/dark cycle). The animals were allowed free access to food and tap water. All experimental procedures of this study were approved by the Medical Research Ethics Committee of Mansoura University, Egypt.

Heart failure following left coronary artery ligation: Myocardial infarction was produced by Coronary Artery Ligation (CAL) according to the method described by Sanbe et al. (1993). Briefly, the animals were anaesthetized with pentobarbital sodium $\left(45 \mathrm{mg} \mathrm{kg}^{-1}\right.$, i.p.), intubated and artificially ventilated with air. The skin was incised along the left sternal border and the fourth rib was cut proximal to the sternum. The pericardial sac was perforated and the heart was exteriorized through the intercostal space. The left coronary artery was ligated approximately $2 \mathrm{~mm}$ from its origin with a suture of 5-0 silk string. The heart was repositioned in the chest and the wound was then sutured with strings. Among the 36 animals that had undergone the operation, 8 died within $24 \mathrm{~h}$ and 4 within 1 week of the operation. The remaining 24 rats were used for the subsequent studies. A sham operation was also performed without CAL in 24 rats. At 1st week after the operation, both CAL rats and shamoperated (Sham) rats were divided into NEP inhibitor (ONO-9902) -treated and untreated groups.

Experimental protocols: In the first series of experiments, acute effects of oral ONO-9902 treatment on sham rats or rats with CAL at the 1st week after the operation were examined. Group I: (12 rats): Included sham operated rats at the 1 st week after the operation. Those rats were further classified into: Ia (6 rats): Included sham operated rats without treatment at the 1 st week after the operation, Ib (6 rats): Included sham operated rats in which acute effects of ONO-9902 (single oral dose of $300 \mathrm{mg} \mathrm{kg}^{-1}$ body weight) (Maki et al., 2001), at the 1st week after the operation, were examined. Group II: (12 rats): Included rats with CAL at the 1 st week after the operation. Those rats were further classified into: IIa (6 rats): Included rats with CAL without treatment at the 1 st week after the operation, IIb (6 rats): Included rats with CAL in which acute effects of ONO-9902 (single oral dose of $300 \mathrm{mg}$ $\mathrm{kg}^{-1}$ body weight) at the 1 st week after the operation were examined.

In the second series of experiments, chronic effects of ONO-9902 treatment on rats with CAL or Sham rats at the 6th week after the operation were examined. Group III: (12 rats): Included sham operated rats at the 6 th week after the operation. Those rats were further classified into: IIIa (6 rats): Included sham operated rats without treatment at the 6th week after the operation, IIIb (6 rats): Included sham operated rats in which chronic effects of ONO-9902 $\left(300 \mathrm{mg}^{-1} \mathrm{~kg}\right.$ body weight day $^{-1}$ from the 1st week, orally) (Maki et al., 2001), at the 
6th week after the operation, were examined. Group IV: (12 rats): Included rats with CAL at the 6th week after the operation. Those rats were further classified into: IVa (6 rats): Included rats with CAL without treatment at the 6th week after the operation, IVb (6 rats): included rats with CAL in which chronic effects of ONO-9902 (300 mg kg-1 body weight day ${ }^{-1}$ from the 1 st week, orally), at the 6th week after the operation, were examined.

Sampling: Blood samples were obtained from rat tail vein under anesthesia with diethylether and divided into two tubes: The first one containing $\mathrm{K}_{2}$ EDTA, mixed well, centrifuged at $7000 \mathrm{rpm}$ for $10 \mathrm{~min}$ to obtain plasma which was stored at $-30^{\circ} \mathrm{C}$ until assay of plasma ANP, cGMP and aldosterone. The second tube contains heparin, centrifuged at $7000 \mathrm{rpm}$ for $10 \mathrm{~min}$. to obtain heparinized plasma for measurement of plasma $\mathrm{Na}$ and creatinine. Rats were housed in metabolic cages for 24 h. to obtain urine samples which are centrifuged for 10 min at $7000 \mathrm{rpm}$ then refrigerated until analysis of urinary ANP, cGMP, Na and creatinine.

Biochemical investigations: Plasma and urinary ANP (AssayMax ELISA Kit, Cat No. ER A7010-1) was measured employing a quantitative sandwich enzyme immune assay technique, according to the manufacturer instruction, using plate reader (Tecan, SunRise Absorbance reader). Plasma Aldosterone Concentration (PAC) (an enzyme labeled immunometric assay, Immulite 2000 Kit, Diagnostic Products Corp.), serum and urinary sodium (Trinder, 1951) and creatinine (colorimetric kits, Spinreact, spain; Ref:1001111) were measured. Glomerular Filtration Rate (GFR) was determined by Creatinine Clearance $(\mathrm{CrCl})$. Also, plasma and urinary cGMP were determined by HighPerformance Liquid Chromatography (HPLC) (Schweinsberg and Loo, 1980). Net renal generation of cGMP was determined using the formula: Net renal generation of cGMP $=$ (urinary cGMP $\mathrm{X}$ urine flow rate)-(plasma cGMP $\mathrm{X}$ creatinine clearance) (Margulies et al., 1995).

Fraction excretion of $\mathrm{Na}^{+}\left(\mathrm{FE}{ }_{\mathrm{Na}}\right.$ ) (Laiken and Fanestil, 1990): $\mathrm{FE}_{\mathrm{Na}}=$ mass of $\mathrm{Na}$ excreted $/$ mass of $\mathrm{Na}$ filtered. Mass of $\mathrm{Na}$ excreted $=\mathrm{U}_{\mathrm{Na}} \cdot \mathrm{V}$, where $\mathrm{U}_{\mathrm{Na}}=$ concentration of $\mathrm{Na}^{+}$in urine $\left(\mathrm{mg} \mathrm{mL}^{-1}\right)$ and $\mathrm{V}=$ volume of urine $\left(\mathrm{mL} \mathrm{min}{ }^{-1}\right)$ while Mass of $\mathrm{Na}$ filtered $=$ GFR. $\mathrm{P}_{\mathrm{Na}}$, where $\mathrm{P}_{\mathrm{Na}}=$ concentration of $\mathrm{Na}^{+}$or $\mathrm{K}^{+}$in plasma $\left(\mathrm{mg} \mathrm{mL}^{-1}\right)$. Therefore, $\mathrm{FE}_{\mathrm{Na}}=\mathrm{V} \cdot \mathrm{U}_{\mathrm{Na}} / \mathrm{P}_{\mathrm{Na}} \cdot \mathrm{GFR}=$ $\mathrm{U}_{\mathrm{Na}} \cdot \mathrm{P}_{\mathrm{cr}} / \mathrm{U}_{\mathrm{cr}} \cdot \mathrm{P}_{\mathrm{Na}}$

RT-PCR of plasma and renal NEP: Total RNA extraction was carried out from rat plasma and kidney, after homogenization, using E.Z.N.A $®$ Blood RNA kit (product \# R6614) provided from Omega Bio-Tek USA., Inc. following the manufacturer's instructions. Semiquantitative Reverse Transcription Polymerase Chain Reaction (RT-PCR) was performed using Readyto-Go. RT-PCR beads for first cDNA synthesis and PCR reaction provided by Amersham Biosciences, England. Cat. No. 27-9266-01, according to the method of Berchtold (Seymour et al., 1990). Gene specific primer for NEP (F-5 - CAG CCT CAG CCG AAA CTA CA-3`.R-5`- TTT GTC TCA GCA TCC ATC CAA-3`) (Pintado et al., 2003) and Internal control GAPDH (house keeping gene) (F-5'GCCATCAACGACCCCTTCATTG-3'.R-5'-T G C C A GTGAGCTTCCCGTTC-3') (Sakai et al., 2000) were purchased from Biolegio. BV, PO Box 91, 5600 AB Nijmegen, Netherlands. Thermal cycling reaction was performed using thermal cycler (Minicycler PTC-150) with the following program: 35 cycles consisting of three steps; denaturation at $95^{\circ} \mathrm{C}$ for $1 \mathrm{~min}$, primer annealing at $55^{\circ} \mathrm{C}$ for $1 \mathrm{~min}$, extension at $72^{\circ} \mathrm{C}$ for 2 min and an additional final extension at $72^{\circ} \mathrm{C}$ for 10 min. The products was subjected to agarose gel electrophoresis using $2 \%$ agarose stained with ethidium bromide and visualized via light UV Transilluminator (Model TUV-20, OWI. Scientific, Inc. 800 242-5560) and photographed under fixed conditions (the distance, the light and the zoom). The RT-PCR products size were as follow: $116 \mathrm{bp}$ and $700 \mathrm{bp}$ for NEP and GAPDH (internal control house-keeping gene) respectively. The results photos were analyzed with scion image $®$ release Alpha 4.0.3.2. software for windows $₫$ which performs bands detection and conversion to peaks. Area under each peak was calculated in square pixels and used for quantification. Gene expression levels were determined by calculating the ratio between the square pixel value of the target gene in relation to the control gene (house keeping gene).

Measurements of hemodynamic parameters: Heart Rate (HR) and Mean Arterial Pressure (MAP) were measured by non-invasive method of rat's tail cuff plethysmography using LE 5001 pressure meter (LETICA Scientific Instrument, Cornella, Barcelona, Spain).

Statistical analysis: The data were expressed as mean \pm standard error of mean (Mean \pm SEM). Data were processed and analyzed using the Statistical Package of Social Science version 10.0 (SPSS, version 10.0). ANOVA was done followed by Fisher's least significant difference test. A minimum level of significance is considered if $\mathrm{P}$ is $\leq 0.05$. 


\section{RESULTS}

Effects of acute treatment with NEPI on plasma and renal NEP gene expressions, plasma concentrations of ANP, aldosterone and cGMP, haemodynamic and renal parameters (Table 1).

With the exception of significant reduction in plasma and renal NEP gene expression (Fig. 1 and 3) in sham rats received acute treatment with NEPI, all other measured parameters (plasma ANP, cGMP and aldosterone levels, MAP, HR, urine volume, sodium and ANP excretion, renal cGMP generation) were non significantly changed (Table 1). Plasma NEP gene expression decreased, plasma ANP, cGMP and aldosterone levels increased significantly in CAL rats without treatment after one week relative to the corresponding sham rats. Acute treatment of CAL rats with NEPI significantly decreased plasma NEP gene expressions (Fig. 1) and increased plasma ANP level and cGMP whereas it caused no significant change in heart rate, MAP and PAC. Heart rate and MAP were non significantly changed in CAL rats with or without treatment (Table 1).

Furthermore, in rats with CAL after one week, despite the non significant decrease in GFR (creatinine clearance), urine volume and sodium excretion significantly decreased which confirmed avid sodium retention (Table 1). Also, in those rats, renal NEP gene expression increased (Fig. 3), urinary ANP non significantly changed whilst renal cGMP generation decreased significantly. Acute treatment of those rats with NEPI caused significant decrease in renal NEP gene expression (Fig. 3), increase in urine volume, sodium and ANP excretion and renal cGMP generation whereas GFR was non significantly changed (Table 1).

Effects of long term treatment with NEPI on plasma and renal NEP gene expressions, plasma concentrations of ANP, aldosterone and cGMP, haemodynamic and renal parameters (Table 2).

All measured parameters in sham rats received long term treatment with NEPI, (plasma ANP, cGMP and aldosterone levels, MAP, HR, urine volume, sodium and ANP excretion, renal cGMP generation) were non significantly changed except significant decrease in plasma and renal NEP gene expression (Table 2, Fig. 2 and 4). While plasma ANP, cGMP and aldosterone in CAL rats were significantly increased relative to sham rats, plasma NEP gene expression was decreased (Fig. 2) and HR and MAP were non significantly changed. Long term treatment with NEPI significantly increased cGMP and decreased PAC and plasma NEP gene expression but no significant change was reported in plasma ANP, HR and MAP (Table 2).

Moreover, in CAL rats after 6 weeks, there was significant increase in renal NEP gene expression (Fig. 4), decrease in urine volume, sodium excretion and renal cGMP generation but no significant change in GFR and urinary ANP excretion. Long term treatment by NEPI significantly decreased renal NEP gene expression (Fig. 4), increased urine volume, sodium and ANP excretions and renal cGMP generation while GFR was non significantly changed (Table 2).

Table 1: Effect of single administration of ONO-9902 on neutral endopeptidase (NEP) gene expression, hormonal, hemodynamic and renal parameters in rats with left Coronary Artery Ligation (CAL) and in sham-operated rats (Sham) at the 1st week after the operation

\begin{tabular}{|c|c|c|c|c|}
\hline & \multicolumn{2}{|l|}{ Sham } & \multicolumn{2}{|l|}{ CAL } \\
\hline & Untreated & Treated & Untreated & Treated \\
\hline \multicolumn{5}{|l|}{ NEP gene expressions: } \\
\hline Plasma NEP /GAPDH mRNA & $0.45 \pm 0.08$ & $0.27 \pm 0.04^{\mathrm{a}}$ & $0.29 \pm 0.03^{\mathrm{b}}$ & $0.14 \pm 0.01^{\mathrm{ab}}$ \\
\hline Renal NEP /GAPDH mRNA & $1.4 \pm 0.09$ & $0.8 \pm 0.06^{\mathrm{a}}$ & $2.7 \pm 0.1^{\mathrm{b}}$ & $1.2 \pm 0.08^{\mathrm{ab}}$ \\
\hline \multicolumn{5}{|l|}{ Plasma ANP, PAC and cGMP: } \\
\hline Plasma ANP (pg mL $\left.L^{-1}\right)$ & $43.7 \pm 3.1$ & $47.2 \pm 4.3$ & $110 \pm 5.7^{b}$ & $155.8 \pm 4.8^{\mathrm{ab}}$ \\
\hline Plasma cGMP $\left(\mathrm{pmol} \mathrm{mL} L^{-1}\right)$ & $4.6 \pm 0.6$ & $4.9 \pm 0.6$ & $10.2 \pm 0.9^{\mathrm{b}}$ & $15.9 \pm 0.7^{\mathrm{ab}}$ \\
\hline PAC $\left(\mathrm{pg} \mathrm{mL}^{-1}\right)$ & $150.4 \pm 5.1$ & $156.4 \pm 5.6$ & $304.2 \pm 7.1^{\mathrm{b}}$ & $296.6 \pm 8.5^{\mathrm{b}}$ \\
\hline \multicolumn{5}{|l|}{ Hemodynamic parameters: } \\
\hline MAP (mmHg) & $95 \pm 7$ & $91 \pm 10$ & $87 \pm 5$ & $82.0 \pm 8$ \\
\hline HR (beats $\min ^{-1}$ ) & $387 \pm 14$ & $408 \pm 10$ & $369 \pm 13$ & $385.0 \pm 12$ \\
\hline \multicolumn{5}{|l|}{ Renal parameters: } \\
\hline Urine flow $\left(\mu \mathrm{L} \mathrm{min}{ }^{-1}\right)$ & $25.5 \pm 4.2$ & $30.2 \pm 3.9$ & $8.4 \pm 1.1^{\mathrm{b}}$ & $19.4 \pm 2.4^{\mathrm{ab}}$ \\
\hline $\mathrm{CrCl}\left(\mathrm{mL} \mathrm{\operatorname {min } ^ { - 1 } )}\right.$ & $1.25 \pm 0.2$ & $1.2 \pm 0.2$ & $0.9 \pm 0.2$ & $0.95 \pm 0.2$ \\
\hline $\mathrm{U}_{\mathrm{Na}} \cdot \mathrm{V} \mu \mathrm{Eq} \min ^{-1}$ & $3.7 \pm 0.3$ & $4.1 \pm 0.3$ & $2.1 \pm 0.1^{\mathrm{b}}$ & $3.5 \pm 0.1^{\mathrm{a}}$ \\
\hline $\mathrm{FE}_{\mathrm{Na}} \%$ & $0.021 \pm 0.002$ & $0.025 \pm 0.003$ & $0.009 \pm 0.001^{\mathrm{b}}$ & $0.018 \pm 0.002^{\mathrm{a}}$ \\
\hline $\mathrm{U}_{\mathrm{ANP}} \cdot \mathrm{V}\left(\mathrm{pg} 24 \mathrm{~h}^{-1}\right)$ & $88 \pm 5.2$ & $95 \pm 6.1$ & $80 \pm 8.7$ & $156.0 \pm 9.1^{\mathrm{ab}}$ \\
\hline Renal cGMP, pmol min ${ }^{-1}$ & $25.7 \pm 3.5$ & $29.6 \pm 3.9$ & $9.7 \pm 0.9^{b}$ & $32.8 \pm 3.3^{\mathrm{a}}$ \\
\hline
\end{tabular}




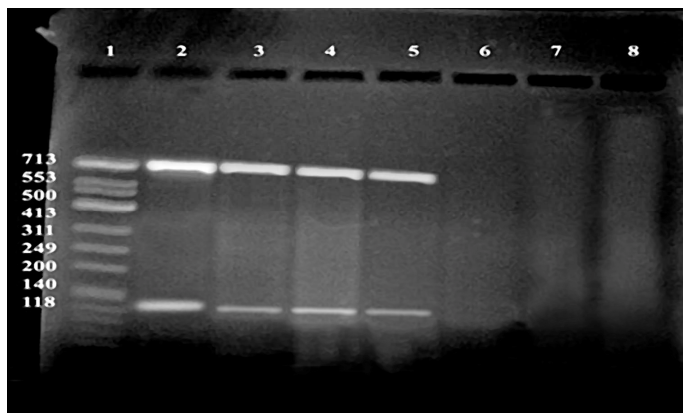

Fig. 1: RT-PCR product of plasma neutral endopeptidase gene expression in relation to GAPDH (internal control house keeping gene) in rats with acute ONO-9902 treatment: Lane1: DNA marker, Lane 2: Sham without treatment, Lane 3: Sham with treatment, Lane 4: CHF without treatment, Lane 5: CHF with treatment, Lane 6: Negative control

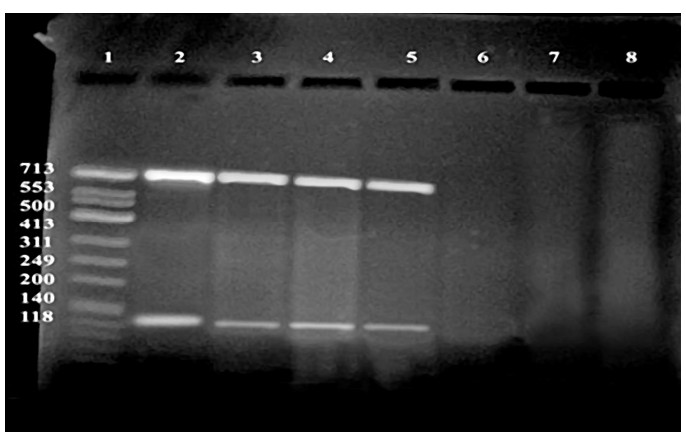

Fig. 2: RT-PCR product of plasma neutral endopeptidase gene expression in relation to GAPDH in rats with chronic ONO-9902 treatment: Lane1: DNA marker, Lane 2: Sham without treatment, Lane 3: Sham with treatment, Lane 4: CHF without treatment, Lane 5: CHF with treatment, Lane 6: Negative control

\section{DISCUSSION}

The present study showed that NEP gene expression, in rats with $\mathrm{CHF}$ induced by CAL, significantly decreased in the plasma (Table 1 and 2, Fig. 1, 2) and increased in kidney (Table 1, 2, Fig. 3,4). Moreover, plasma ANP level significantly increased in these rats (Table 1,2), due to decreased plasma NEP gene expression (Table 1, 2, Fig. 1, 2). In spite of the elevation in plasma ANP level, urinary ANP excretion is not significantly changed (Table 1,2 ). This could be explained by the significant increase in renal NEP gene expression (Table 1, 2, Fig. 3, 4) in CHF which increases the degradation of endogenous ANP.

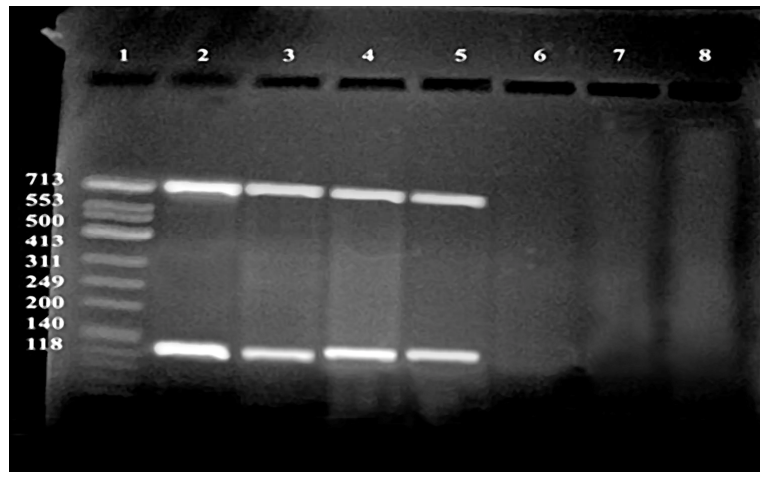

Fig. 3: RT-PCR product of renal neutral endopeptidase gene expression in relation to GAPDH in rats with acute ONO-9902 treatment: Lane1: DNA marker, Lane 2: Sham without treatment, Lane 3: Sham with treatment, Lane 4: CHF without treatment, Lane 5: CHF with treatment, Lane 6: Negative control

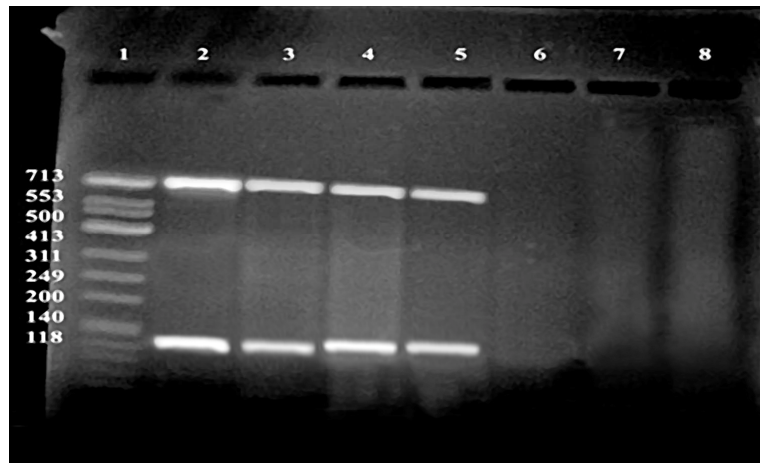

Fig. 4: RT-PCR product of renal neutral endopeptidase gene expression in relation to GAPDH in rats with chronic ONO-9902 treatment: Lane1: DNA marker, Lane 2: Sham without treatment, Lane 3: Sham with treatment, Lane 4: CHF without treatment, Lane 5: CHF with treatment, Lane 6: Negative control

This enhanced renal degradation of endogenous ANP in CHF may results in the attenuated renal natriuretic response to natriuretic peptides in $\mathrm{CHF}$, supporting the concept of NEP inhibition in heart failure therapy. Our results were in agreement with Knecht et al. (2002). The responsible mechanism for elevated renal NEP expression is not entirely clear. Knecht et al. (2002) observed increased renal NEP mRNA levels in rats with myocardial infarction, suggesting that transcriptional activation of the NEP gene may contribute to the increased protein concentration and activity of NEP. 
Am. J. Applied Sci., 7 (11): 1449-1457, 2010

Table 2: Effects of long-term treatment with ONO-9902 on neutral endopeptidase (NEP) gene expression, hormonal, haemodynamic and renal parameters, in rats with left Coronary Artery Ligation (CAL) and in sham-operated rats (Sham) at the 6th week after the operation

\begin{tabular}{|c|c|c|c|c|}
\hline & \multicolumn{2}{|l|}{ Sham } & \multicolumn{2}{|l|}{ CAL } \\
\hline & Untreated & Treated & Untreated & Treated \\
\hline \multicolumn{5}{|l|}{ NEP gene expressions: } \\
\hline Plasma NEP /GAPDH mRNA & $0.51 \pm 0.06$ & $0.25 \pm 0.04^{\mathrm{a}}$ & $0.24 \pm 0.02^{\mathrm{b}}$ & $0.11 \pm 0.03^{\mathrm{ab}}$ \\
\hline Renal NEP /GAPDH mRNA & $1.5 \pm 0.08$ & $0.7 \pm 0.06^{\mathrm{a}}$ & $2.9 \pm 0.1^{\mathrm{b}}$ & $1.1 \pm 0.08^{\mathrm{ab}}$ \\
\hline \multicolumn{5}{|l|}{ Plasma ANP, PAC and cGMP: } \\
\hline Plasma ANP (pg mL $\left.{ }^{-1}\right)$ & $47.1 \pm 7.7$ & $53.3 \pm 8.7$ & $171.8 \pm 12.5^{\mathrm{b}}$ & $179.8 \pm 11.8^{\mathrm{b}}$ \\
\hline Plasma cGMP (pmol mL $\left.{ }^{-1}\right)$ & $5.1 \pm 0.6$ & $5.5 \pm 0.6$ & $14.2 \pm 0.9^{\mathrm{b}}$ & $24.9 \pm 0.7^{\mathrm{ab}}$ \\
\hline $\operatorname{PAC}\left(\mathrm{pg} \mathrm{mL}^{-1}\right)$ & $156.6 \pm 5.3$ & $161.2 \pm 5.8$ & $390.2 \pm 8.6^{\mathrm{b}}$ & $195.8 \pm 8.5^{\mathrm{ab}}$ \\
\hline \multicolumn{5}{|l|}{ Hemodynamic parameters: } \\
\hline MAP (mmHg) & $99 \pm 4$ & $93 \pm 3$ & $92 \pm 4$ & $100 \pm 4$ \\
\hline HR (beats $\min ^{-1}$ ) & $385 \pm 9$ & $371 \pm 6$ & $377 \pm 7$ & $386 \pm 7$ \\
\hline \multicolumn{5}{|l|}{ Renal parameters: } \\
\hline Urine flow $\left(\mu \mathrm{L} \min ^{-1}\right)$ & $27.5 \pm 4.6$ & $33.2 \pm 3.9$ & $5.5 \pm 1.2^{\mathrm{b}}$ & $22.5 \pm 2.5^{\mathrm{ab}}$ \\
\hline $\mathrm{CrCl}\left(\mathrm{mL} \min ^{-1}\right)$ & $1.3 \pm 0.3$ & $1.2 \pm 0.2$ & $0.8 \pm 0.3$ & $0.9 \pm 0.3$ \\
\hline $\mathrm{U}_{\mathrm{Na}} . \mathrm{V} \mu \mathrm{Eq} \min ^{-1}$ & $3.8 \pm 0.3$ & $4.3 \pm 0.4$ & $1.0 \pm 0.1^{\mathrm{b}}$ & $2.9 \pm 0.1^{\mathrm{ab}}$ \\
\hline $\mathrm{FE}_{\mathrm{Na}} \%$ & $0.022 \pm 0.002$ & $0.026 \pm 0.003$ & $0.004 \pm 0.001^{\mathrm{b}}$ & $0.02 \pm 0.002^{\mathrm{a}}$ \\
\hline $\mathrm{U}_{\mathrm{ANP}} \cdot \mathrm{V}\left(\mathrm{pg} 24 \mathrm{~h}^{-1}\right)$ & $93 \pm 5.4$ & $101 \pm 6.1$ & $105 \pm 8.7$ & $233 \pm 8.4^{\mathrm{a}}$ \\
\hline Renal cGMP, pmol min ${ }^{-1}$ & $28.8 \pm 2.1$ & $32.2 \pm 2.4$ & $8.5 \pm 0.7^{b}$ & $34.8 \pm 2.3^{\mathrm{a}}$ \\
\hline
\end{tabular}

Values were given as mean \pm SEM for groups of 6 rats each. ${ }^{a}: p<0.05$ relative to the corresponding untreated group, ${ }^{b}: p<0.05$ relative to the corresponding sham group. ANP: Atrial Natriuretic Peptide, PAC: Plasma Aldosterone Concentration, MAP: Mean Arterial Pressure, HR: Heart Rate, $\mathrm{CrCl}$ : Creatinine Clearance, $\mathrm{U}_{\mathrm{Na}} \mathrm{V}$ : Na excretion, $\mathrm{FE}_{\mathrm{Na}} \%$ : Fraction Excretion of $\mathrm{Na}, \mathrm{U}_{\mathrm{ANP}} . \mathrm{V}$ : ANP excretion

Moreover, decreased renal generation of cGMP, the second messenger of ANP, with increased PAC, ANP counter-regulatory hormone, in rats with untreated $\mathrm{CHF}$ (Table 1,2) lead to renal resistance to the natriuretic action of ANP in CHF. These results were in accord with previous reports (Knecht et al., 2002; Bryan et al., 2007). Therefore, the current study also importantly extends our understanding of the renal hyporesponsiveness to elevated concentrations of endogenous ANP in CHF. Previous studies have suggested that the attenuated natriuretic response to elevated plasma ANP in CHF may be related to ANP receptor down-regulation, enhanced degradation and clearance of ANP, altered postreceptor signal transduction and activation of counter-regulatory neurohumoral systems such as renal nerves and the intrarenal renin angiotensin system as well as decreased renal perfusion pressure (Charloux et al., 2003; Korinek et al., 2008).

The present study showed a significant decrease in urinary sodium excretion and urine volume in rats with CAL despite the non significant change in GFR (Table 1, 2) which indicate sodium and water retention. The marked increase in PAC and decrease in fractional excretion of sodium with preserved GFR in CHF (Table 1,2) indicates that increasing tubular sodium reabsorption was responsible for this avid sodium retention in CHF. No significant changes were observed in MAP or heart rate.

In the sham rats, acute or long term treatment with ONO-9902 also diminished the plasma (Table 1,
2, Fig. 1,2) and renal NEP gene expression (Table 1, 2, Fig. 3,4) but the plasma ANP concentration was not increased (Table 1, 2). It is considered that the inactivation of circulating ANP is attributed to clearance receptor-mediated internalization and/or enzymatic degradation of these peptides and that NEP plays a major role in the clearance of ANP when its plasma concentration in the animals with heart failure is high (Charloux et al., 2003; Kimura et al., 2007). Therefore, it is conceivable that NEP inhibitors may enhance the biological activity of endogenous ANP and thereby produce the favorable effect only when the plasma ANP level is high.

A single administration of ONO-9902 in rats with CAL leads to inhibition of the plasma (Table 1, Fig. 1) and renal NEP gene expression (Table 1, Fig. 3), which was accompanied by a significant elevation of the plasma ANP concentration (Table 1). This is consistent with the effects of the NEP inhibitor ecadotril (sinorphan), a NEP inhibitor that is an orally active prodrug of (S)-thiorphan, on the plasma NEP activity and the ANP concentration in rats with heart failure produced by aortovenocaval (AV) fistula as reported by Wegner et al. (1996). Also, our results demonstrate that chronic administration of ONO-9902 resulted in inhibition of the plasma (Table 2, Fig. 2) and renal NEP gene expression (Table 2, Fig. 4). Furthermore, the elevation in plasma ANP concentration, in rats with CHF induced by CAL, was further increased but non significantly by chronic treatment with NEPI, ONO9902 for 6 weeks (Table 2). Maki et al. (2001) observed 
reduction in the plasma ANP and BNP concentrations following chronic treatment of rats with CHF by NEPI. Moreover, as the plasma concentrations of ANP and BNP are sensitive indices for the severity of heart failure (Tsutamoto et al., 1997), therefore, they consider the reduction in the plasma ANP and BNP concentrations following chronic treatment with NEPI to be as a result of the improvement of the pathophysiology of CHF. In the current study, the significant reduction of plasma and renal NEP mRNA of sham or CAL rats on treatment with NEPI, ONO9902, indicated that ONO-9902 inhibited the NEP activity irrespective of the presence or absence of CAL.

The current study showed that acute treatment of CAL rats with NEPI caused diuresis and natriuresis, increased plasma and urinary ANP and renal cGMP generation while GFR was preserved (Table 1). Moreover, chronic treatment of rats with CAL by NEPI significantly increased urine volume, sodium excretion, urinary ANP level, renal cGMP generation in spite of the non significant change in plasma ANP level and GFR (Table 2). The mechanisms of these renal diuretic and natriuretic actions of NEPI, despite preserved GFR, most likely are linked to enhanced renal action of filtered ANP at the level of the renal tubule as renal NEP gene expression significantly decreased (Fig. 3, 4), which decreases ANP degradation and also renal cGMP generation increased in NEPI treated CHF rats as compared to the untreated group in the absence of any higher level of GFR (Table 1,2). Therefore, increased urinary excretion of ANP, secondary to inhibition of its degradation by renal NEPI, with increased renal cGMP generation in CAL treated rats suggests that NEPI potentiates the attenuated local renal responses to ANP action which leads to a decrease in sodium reabsorption at nephron sites known to be responsive to ANP. Such local potentiation of ANP action by NEP-I in the present work is consistent with previous studies (Margulies et al., 1995; Cavero et al., 1990). NEP-I did not cause significant changes in HR and MAP. These results suggest that NEP-I in CHF has a selective renal action independent of changes in MAP or HR.

An additional important finding is that chronic NEPI reduced markedly the PAC confirming the results reported by Martin et al. (2005) who found, in severe experimental chronic heart failure, a marked decrease in the plasma aldosterone level with chronic oral NEPI treatment. Based upon the known high expression of the natriuretic peptide $A$ receptor in the zona glomerulosa of the adrenal gland, the mechanism of aldosterone suppression with chronic NEPI may involve ANP (Martin et al. (2005). Aldosterone increases tubular sodium reabsorption in inner medullary collecting duct cells which is also the site of action of ANP. Kenny and Stephenson (1988) reported that NEP-I inhibits the degradation of ANP in the proximal tubule where NEP is abundant, therefore allowing pharmacological rather than physiological concentrations of intact ANP to reach more distal segments of the nephron specifically the inner medullary collecting duct (Charloux et al., 2003) where ANP receptors are abundant, thus antagonizing the actions of aldosterone while also decreasing aldosterone release. Therefore, exaggerated decrease in distal fractional reabsorption was predicted based on the known presence of ANP receptors at the level of the terminal nephron (Sonnenberg et al., 1990) Indeed, our studies support such a conclusion.

\section{CONCLUSION}

In conclusion, there is an increase in the plasma ANP concentration in CHF. Long-term NEP-I decreases $\mathrm{Na}$ and water retention in rats with $\mathrm{CHF}$ probably by decreasing the degradation effect of NEP on ANP with the consequence of increased plasma ANP level and inhibiting aldosterone secretion. Accordingly, NEP-I, in CHF, acts to decrease tubular reabsorption of sodium in this sodium-retaining state, inducing diuresis and natriuresis. This action appears independent of changes in systemic or renal hemodynamics. Therefore, NEP-I may serve as a new therapeutic approach to enhance the renal natriuretic action of elevated endogenous ANP in patients with CHF.

\section{REFERENCES}

Arnolda, L., B.P. McGrath and C.I. Johnston, 1991. Vasopressin and angiotensin II contribute equally to the increased afterload in rabbits with heart failure. Cardiovasc. Res., 25: 68-72. PMID: 2054832

Bryan, P.M., X. Xu, D.M. Dickey, Y. Chen and L.R. Potter, 2007. Renal hyporesponsiveness to atrial natriuretic peptide in congestive heart failure results from reduced atrial natriuretic peptide receptor concentrations. Am. J. Physiol. Renal Physiol., 292: 1636-1644. PMID: 17264312

Cavero, P.G., K.B. Margulies, J. Winaver, A.A. Seymour and N.G. Delaney et al., 1990. Cardiorenal actions of neutral endopeptidase inhibition in experimental congestive heart failure. Circulation, 82: 196-201. http://circ.ahajournals.org/cgi/content/short/82/1/196

Charloux, A., F. Piquard, S. Doutreleau, G. Brandenberger and B. Geny, 2003. Mechanisms of renal hyporesponsiveness to ANP in heart failure. Eur. J. Clin. Invest., 33: 769-778. PMID: 12925036 
Clerico, A. and M. Emdin, 2004. Diagnostic accuracy and prognostic relevance of the measurement of cardiac natriuretic peptides: A review. Clin. Chem., 50: 33-50. DOI: 10.1373/clinchem.2003.024760

Colucci, W.S., U. Elkayam, D.P. Horton, W.T. Abraham and R.C. Bourge et al., 2000. Intravenous nesiritide, a natriuretic peptide, in the treatment of decompensated congestive heart failure. Nesiritide Study Group. New Engl. J. Med., 343: 246-253. PMID: 10911006

Hashimoto, Y., K. Nakao, N. Hama, H. Imura and S. Mori et al., 1994. Clearance mechanisms of atrial and brain natriuretic peptides in rats. Pharm. Res., 11: 60-64. DOI: 10.1023/A:1018941626731

Kenny, A.J. and S.L. Stephenson, 1988. Role of endopeptidase-24.22 in the inactivation of atrial natriuretic peptide. FEBS. Lett., 232: 1-8. PMID: 2966745

Kilic, A., A. Bubikat, B. Gabner, H.A. Baba and M. Kuhn, 2007. Local actions of atrial natriuretic peptide counteract angiotensin II stimulated cardiac remodeling. Endocrinology, 148: 4162-4169. DOI: 10.1210/en.2007-0182

Kimura, K., Y. Yamaguchi, M. Horii, H. Kawata and H. Yamamoto et al., 2007. ANP is cleared much faster than BNP in patients with congestive heart failure. Eur. J. Clin. Pharmacol., 63: 699-702. DOI: 10.1007/s00228-007-0309-1

Knecht, M., I. Pagel, T. Langenickel, S. Philipp and M. Scheuermann-Freestone et al., 2002. Increased expression of renal neutral endopeptidase in severe heart failure. Life Sci., 71: 2701-2712. PMID: 12383878

Korinek, J., G. Boerrigter, S.F. Mohammed and J.C. Burnett Jr, 2008. Insights into natriuretic peptides in heart failure: An update. Current Heart Failure Rep., 5: 97-104. DOI: 10.1007/s11897-0080016-y

Laiken, N. and D.D. Fanestil, 1990. Body Fluids and Renal Function. In: Best and Taylor`s Physiological Basis of Medical Practice, West, J.B. (Ed.). Williams and Wilkins. Philadelphia, pp: 406-512.

Lainscak, M., M.S. Anker, S. Von Haehling and S.D. Anker, 2009. Biomarkers for chronic heart failure. diagnostic, prognostic and therapeutic challenges. Herz, 34: 589-93. PMID: 200246374

Maki, T., T. Horio, F. Yoshihara, S. Suga and S. Takeo et al., 2000. Effect of neutral endopeptidase inhibitor on endogenous atrial natriuretic peptide as a paracrine factor in cultured cardiac fibroblasts. Br. J. Pharmacol., 131: 1204-1210. DOI: 10.1038/sj.bjp.0703679
Maki, T., Y. Nasa, F. Yamaguchi, H. Yoshida and M. Mori et al., 2001. Long-term treatment with neutral endopeptidase inhibitor improves cardiac function and reduces natriuretic peptides in rats with chronic heart failure. Cardiovasc. Res., 51: 608-617. DOI: 10.1016/S0008-6363(01)00258-9

Margulies, K.B., P.L. Barclay and J.J.C. Burnett, 1995. The role of neutral endopeptidase in dogs with evolving congestive heart failure. Circulation, 91: 2036-2042. http://circ.ahajournals.org/cgi/content/full/91/7/2036

Martin, F.L., T.L. Stevens, A. Cataliotti, J.A. Schirger and D.D. Borgeson et al., 2005. Natriuretic and antialdosterone actions of chronic oral NEP inhibition during progressive congestive heart failure. Kidney Int., 67: 1723-1730. PMID: 15840018

Palazzuoli, A. and R. Nuti, 2010. Heart failure: Pathophysiology and clinical picture. Contrib. Nephrol., 164: 1-10. PMID: 20427988.

Pintado, C.O., F.M. Pinto, J.N. Pennefather, A. Hidalgo and A. Baamonde et al., 2003. A role for tachykinins in female mouse and rat reproductive function. Biol. Reprod., 69: 940-946. PMID: 12773411

Sakai, S., T. Miyauchi and I. Yamaguchi, 2000. Longterm endothelin receptor antagonist administration improves alterations in expression of various cardiac genes in failing myocardium of rats with heart failure. Circulation, 101: 2849-2853. http://circ.ahajournals.org/cgi/content/full/101/24/2849

Sanbe, A., K. Tanonaka, Y. Hanaoka, T. Katoh and S. Takeo, 1993. Regional energy metabolism of failing hearts following myocardial infarction $\mathrm{J}$. Mol. Cell Cardiol., 25: 995-1013. DOI: 10.1006/jmcc.1993.1113

Sansoe, G.G., M. Aragno, R. Mastrocola, J.C. Cutrin and S. Silvano et al., 2006. Overexpression of kidney neutral endopeptidase (EC 3.4.24.11) and renal function in experimental cirrhosis. Am. J. Physiol. Renal Physiol., 290: 1337-1343. DOI: 10.1152/ajprenal.00435.2005

Schweinsberg, P.D. and T.L. Loo, 1980. Simultaneous analysis of ATP, ADP, AMP and other purines in human erythrocytes by high-performance liquid chromatography. J. Chromatogr., 181: 103-107. PMID: 7364902

Seymour, A.A., J.A. Norman, M.M, Asaad, S.A. Fennell, J.N. Swerdel et al., 1990. Renal and depressor effects of SQ 29,072, a neutral endopeptidase inhibitor, in conscious hypertensive rats. J. Cardiovasc. Pharmacol., 16: 163-172. PMID: 1696660 
Sica, D.A., 2006. Sodium and water retention in heart failure and diuretic therapy: Basic mechanisms. Cleve. Clin. J. Med., 73: 2-7. DOI: 10.3949/ccjm.73.Suppl_2.S2

Sonnenberg, H., U. Honrath and D.R. Wilson, 1990. In vivo microperfusion of inner medullary collecting duct in rats: effect of amiloride and ANF. Am. J. Physiol., 259: 222-226. http://ajprenal.physiology.org/cgi/reprint/259/2/F222

Trinder, P., 1951. A rapid method for the determination of sodium in serum. Analyst, 76: 596-599. DOI: 10.1039/AN9517600596

Tsutamoto, T., A. Wada, K. Maeda, T. Hisanaga and Y. Maeda et al., 1997. Attenuation of compensation of endogenous cardiac natriuretic peptide system in chronic heart failure: Prognostic role of plasma brain natriuretic peptide concentration in patients with chronic symptomatic left ventricular dysfunction. Circulation, 96: 509-516. PMID: 9244219
Wegner, M., C. Hirth-Dietrich and J.P. Stasch, 1996. Role of neutral endopeptidase 24.11 in AV fistular rat model of heart failure. Cardiovasc. Res., 31: 891-898. PMID: 8759244

Wei, C.M., D.M. Heublein, M.A. Perrella, A. Lerman and R.J. Rodeheffer et al., 1993. Natriuretic peptide system in human heart failure. Circulation, 88: 1004-1009. PMID: 8353861

Yamamori, Y., Y. Saito, M. Kaneko, Y. Kirihara and S. Sakura et al., 1996. Antinociceptive effects of ONO-9902, an enkephalinase inhibitor, after visceral stress condition in rats. Can. J. Anaesth., 43:

1175-1179. http://www.springerlink.com/content/cg230132124 681x7/fulltext.pdf

Al-Attar, A.M., 2010. Physiological study on the effect of acalypha wilkesiana leaves extract on streptozotocin-induced experimental diabetes in male mice. Am. Med. J., 1: 51-58. DOI: 10.3844/amjsp.2010.51.58 